\title{
NEDERLAND EN ENGELAND OP KOLONIAAL MUNTGEBIED.
}

Is men, zooals door Prof. Verryn Stuart in zijn levensbericht van Mr. N. G. Pierson, opgenomen in den bundel levensberichten van de Maatschappij der Nederlandsche letterkunde te Leiden, gevraagd wordt, bij de voor onze Indische bezittingen verordende, op eenheid van muntwezen tusschen moederland en kolonie gegronde muntverordeningen, de wetten namelijk van 1 Mei 1854 en 28 Maart 1877, niet te ver gegaan door de Indische standaardmunten zelfs niet uiterlijk te onderscheiden van de Nederlandsche, en kan op grond hiervan beweerd worden, dat Engeland in dit opzicht met betrekking tot het muntwezen van Britsch-Indië in gunstiger toestand verkeert dan dit met ons land tegenover Nederlandsch-Indië het geval is?

Ik meen het te mogen betwijfelen, en van deze mijne opvatting wil ik trachten rekenschap te geven in de volgende beschouwingen tot het op papier brengen waarvan mij ook aanleiding gaf het ter zitting der Eerste Kamer van 29 October 1912 verhandelde over onze muntaangelegenheden.

Men kent het verschil, waarop het ten deze in hoofdzaak aankomt. Britsch-Indië heeft van oudsher een eigen zelfstandig muntwezen met als rekeningseenheid de ropij, die, althans sedert Juni 1893, alleen in de daar te lande nog bestaande muntinrichtingen te Bombay en Calcutta voor rekening der Regeering mag worden geslagen, doch die in Engeland zelf niet als betaalmiddel gangbaar is. Het Nederlandsch-Indische muntwezen daarentegen is, de pasmunt daargelaten, volkomen gelijk en gelijkvormig met het moederlandsche, zoodat de ginder in omloop zijnde standpenningen, zoo gouden als zilveren, hier te lande hun volle betaalkracht blijven behouden. 
De reden nu van dit inderdaad zeer in het oog loopende verschil in toestand is van zuiver historischen aard.

In Britsch-Indië vonden de Engelschen reeds dadelijk bij hun eerste optreden, aanvankelijk als eenvoudige kooplieden, en later als beheerschers van het uitgestrekte gebied, dat zij gaandeweg aan hun gezag wisten te onderwerpen, een wel is waar allerminst volmaakt, maar toch bruikbaar inheemsch muntwezen, dat zij van lieverlede wisten te verbeteren totdat aan de hier en daar nog bestaande verwarring en onzekerheid voor goed een eind werd gemaakt door de onder het bestuur van den Gouverneur-Generaal Lord Bentinck verordende murtregeling van 17 Augustus 1835, krachtens welke van dat oogenblik af alleen de Compagnie's ropij met de halve ropij en de dubbele ropij als wettig betaalmiddel ter voldoening van alle onderlinge transactiën zou mogen dienst doen. Ten gerieve van wie het verlangen mochten konden ook nog gouden mohurs worden aangemunt; maar het verkeer zou er niet door verstoord of verward worden, want art. 9 der nieuwe muntregeling hield de bepaling in, dat voortaan geen gouden munt wettig betaalmiddel zou zijn in eenig gedeelte van het gebied der Oost-Indische Compagnie. Men heeft dus daar te lande nooit te doen gekregen met de in het moederland gebruikelijke betaalmiddelen; daar heeft men in den omloop nooit gekend noch ponden, noch shillings, noch pence, noch farthings, omdat in de eerste plaats de uitvoer van landsmunten uit Engeland naar Indië aan de Compagnie bij het haar verleende octrooi was verboden, en aan den invoer er van in Indie bovendien niet de minste behoefte bestond, daar men zich uitnemend wist te gerieven met de van oudsher in Hindoestan gebruikelijke inheemsche ruilmiddelen, in de behoefte waaraan geregeld voorzien werd door vermunting van aangevoerde zilveren baren of zilveren vreemde munten.

Geheel anders nu was het in dit opzicht gesteld voor onze voorouders bij hunne eerste aanrakingen met de toenmalige bewoners van het land, dat tegenwoordig als Nederlandsch-Indië een deel van het Rijk uitmaakt. Al dadelijk moest men zich voor het aanknoopen van handelsbetrekkingen met "de vreemde landen en de koninkrijken gelegen voorbij de Cabo de Bonne Esperance" voorzien 
van de aldaar door de Portugeezen in zwang gebrachte realen van achten, eene ten cnzent in het laatst der zestiende en het begin der zeventiende eeuw bij verschillende verordeningen van de Staten-Generaal tegen daarbij vastgestelde tarieven als wettig betaalmiddel erkende en veel gebruikte munt, die men of uit Spanje en Portugal ontbood, of hier te lande liet aanmaken krachtens hiertoe door de overheid verleende speciale machtigingen; maar het verkrijgen van realen ging dikwerf gepaard met veel "fastidie en verlet", zooals de Bewindhebberen van de Compagnie het in hunne aanschrijving van 10 December 1622 aan de autoriteiten in Indië uitdrukten, en van daar dat haar bij datzelfde schrijven den last gegeven werd alle mogelijke vlijt aan te wenden om "onse lands munte allerwege daert mogelyck ende practicakel sal wezen in treyn en ganck te brengen". Zoodoende bestond dus schier van den aanvang af eenheid van muntwezen tusschen het moederland en het nieuw verworven handelsgebied in den Indischen archipel, dat gaandeweg als overstroomd werd met allerlei Nederlandsche munten, gouden, zilveren en koperen, koperen vooral, en hierin ligt de naaste aanleiding van de noodlottige begripsverwarringen, die de oorzaak werden van al de verwikkelingen en tegenstrijdigheden op muntgebied, waarmede Indië meer dan twee eeuwen lang heeft te kampen gehad, en waaraan eerst een eind is gemaakt door de wet van 1 Mei 1854, die aan Nederlandsch-Indië in hoofdzaak hetzelfde muntstelsel heeft geschonken dat bij de wet van 26 November 1847 voor Nederland was aangenomen. Dank zij dien maatregel kwam, om de uitdrukking te bezigen van den oud-Gouverneur Generaal Rochussen ter zitting van de Tweede kamer van 26 November 1859, „Java voor het eerst sedert het eene bezitting van Nederland was in het genot van een goed muntstelsel", en de daarmede toen bekrachtigde eenheid van muntwezen tusschen moederland en kolonie is sedert voor Indië een niet hoog genoeg te waardeeren zegen gebleven, ')

1) Immers indien van 1854 af b.v. het met Indischen stempel voorziene in Indië omloopende zilver niet meer voor betaalmiddel in Nederland had kunnen gebruikt worden, hoe zou dan de toestand in Indië geweest zijn bij dringencle behoefte aan remise, 
terwijl die munteenheid vroeger op haar geweten had al de door Ned.-Indië geleden onnoemelijke ellende, waarvoor de bevolking van Britsch-Indie is gespaard gebleven, totdat zij nu laatstelijk ten gevolge van de verstoorde waardeverhouding tusschen haar zilveren ruilmiddel en het gouden ruilmiddel van het moederland insgelijks een benarden tijd heeft door te maken gehad.

Bij de aanleidende oorzaken hiervan, het besluit van Duitschland om het goud tot eenigen grondslag van zijn muntwezen aan te nemen en in verband hiermede alle verdere aanmuntingen van zilveren standpenningen te staken, behoeft hier thans niet opzettelijk te worden stilgestaan. In tal van geschriften, officieele en niet officieele, is de maatregel van alle kanten beschouwd en toegelicht; maar wel is het ter beantwoording van de vraag, waarmede dit opstel aanvangt, onvermijdelijk om na te gaan tot welke maatregelen men in beide landen de toevlucht heeft genomen om de op het spel staande belangen van land en volk zooveel mogelijk voor gevaren te vrijwaren. Beginnen wij met Nederland.

Nadat aanvankelijk op advies van de bij Koninklijk besluit van 30 October 1872 ingestelde Staatscommissie (ten einde te onderzoeken welke nadeelen voor Nederland te duchten waren tengevolge van de maatregelen, die in den laatsten tijd, in 't bijzonder in Duitschland op het gebied van het muntwezen genomen waren, en, zoo noodig de middelen voor te stellen, die zouden kunnen worden aangewend om de voor Nederland gevreesde nadeelen te voorkomen) schier algemeen de opvatting was gehuldigd, dat in de bezittingen in Oost-Indië de zilveren standaard van kracht

zooals dit in de sedert verloopen jaren bij herhaling het geval is geweest? Ik behoef er, geloof ik, hier niet meer van te zeggen, en meen ter zake te mogen verwijzen naar mijn voor de Dictionary of Political Economy van Inglis Palgrave bewerkt artikel: «Exchange between Holland and Dutch India»; deel I, p. 773. In een van zijne naar aanleiding hiervan ontvangen brieven noemde hij het behandelde onderwerp «one of the most intricate exchange problems that I know of, daarbij erkennende, "that Holland had acted very skillfully in its own case». 
blijven moest, welke veranderingen ook in het muntstelsel van het moederland mochten gebracht worden, begon men naar aanleiding van de tegen deze conclusie ingebrachte betoogen uit Indië van lieverlede in te zien, dat, zooals in het Voorloopig Verslag van de Tweede Kamer van 13 Juli 1876 over de toen bij haar aanhangig gemaakte nadere bepalingen omtrent het Indische muntwezen gezegd werd, „indien de waarde van het zilver "in die mate aan daling en fluctuatie onderworpen is, dat "het op den duur voor muntmetaal ongeschikt moet worden "geacht, het niet kan aangaan het voortdurend in Indië als "zoodanig te blijven gebruiken", en toen dan ook bij de wet van 6 Juni 1875 de questie van het muntwezen voor Nederland in dien zin was geregeld, dat voortaan het goud de grondslag van dat muntwezen zou zijn, met vrijheid aan een ieder om voor eigen rekening goud.te doen aanmunten, terwijl daarentegen de vrije aanmunting van zilver verboden bleef, doch het in omloop zijnde zilver naast het goud als algemeen wettig betaalmiddel zou blijven dienst doen, duurde het niet lang meer of bij de wet van 28 Maart 1877 werd hetzelfde stelsel op Nederlandsch-Indië toegepast, zooals het daar thans evenals hier te lande nog van kracht is, daargelaten de voor beide deelen van het Rijk getroffen muntvoorzieningen bij de wetten van 31 October 1912, Stbl. No 324 en 325.

$\mathrm{Nu}$ moge om redenen, die ik eerbiedig, doch waarmede ik voor mij nooit vrede gehad heb, in de wet van 1901 ter codificeering van ons muntwezen de beginselverklaring, dat het goud de eenige grondslag van dat muntwezen is, achterwege zijn gelaten, dit doet in geen enkel opzicht te kort aan de verantwoordelijkheid van de Regeering voor de goudwaarde van al het in den loop der jaren in 's Rijks Munt te Utrecht geslagen zilvergeld, ook voorzoover dat zilver een uitweg heeft gevonden naar Indië, want door de wet van 1877, waarbij voor Indië de gouden standaard werd aangenomen, heeft, volgens de verklaring van den kant der Tweede Kamer in haar Voorloopig Verslag van 7 Maart 1877, „de Nederlandsche Staat zich verbonden jegens "de houders van zilver in Nederlandsch-Indië tot inwisseling "- ingeval van ontmunting - op denzelfden voet als dit 
"aan de houders van zilver in het moederland bereids was "gewaarborgd". Hierop rust het crediet dat Indië geniet, en in zijne tegenwoordige phase van ontwikkeling meer dan ooit noodig heeft. Het ware toch de economische ondergang en ditmaal de onvermijdelijke inzinking van Indië, indien het niet langer onwrikbaar mocht vaststaan, dat bij een eventueelen ommekeer in den stand zijner betalingsbalans, ter aanzuivering van zijne geldelijke verplichtingen tegenover het buitenland, vier zilveren rijksdaalders volkomen dezelfde betaalkracht hebben als een gouden tienguldenstuk. Terugvloeiing naar het moederland van het in Indië omloopende zilvergeld is derhalve allerminst ondenkbaar, en is het nu voor onze Engelsche naburen niet een groote gerustheid en een wezenlijk voorrecht, dat zij zich voor eene dergelijke eventualiteit niet ongerust behoeven te maken? Ik kan het niet inzien en heb thans van deze mijne opvatting nader rekenschap te geven, waartoe de volgende uiteenzetting van den thans na veel pokken en mazelen zich ontwikkeld hebbenden munttoestand in Britsch-Indië mij noodig voorkomt.

$\mathrm{Nu}$ weldra veertig jaren geleden, toen het eene uitgemaakte zaak kon heeten, dat de Nederlandsche Regeering geen middel onbeproefd zou laten om het door haar voor onze Indische bezittingen verordende muntwezen te beschermen tegen de gevolgen, die voor het wereldverkeer te duchten stonden van de verstoorde waardeverhouding tusschen het goud en het zilver, waartoe de in Duitschland ondernomen munthervorming den stoot had gegeven, sprak ik de verwachting uit, dat Engeland, waar men veelal uit de hoogte pleegt neer te zien op de gedragslijn die Nederland tegenover zijn koloniën volgde, door het voorbeeld van Nederland zou worden aangespoord om, met terzijdestelling van de engere belangen der Engelsche geldmarkt, ten behoeve van zijn rijk in Indië te doen wat eene eerlijke en de algemeene belangen van zijne onderdanen behartigende regeering betaamt. ${ }^{1}$ ) Maar ik zag mij in deze

1) De praktische zijde der muntquaestie; in het Algemeen Dagblad van N. I. van 11. Juli 1876 . 
verwachting deerlijk teleurgesteld. Vertrouwende op de meening door den toenmaligen redacteur van den Londenschen Economist Walther Bagehot bij herhaling bepleit en verdedigd, "that the fall in the price of silver would work its own cure", - eene meening, die toenmaals in Engeland vrij algemeen weerklank vond, -- bleef de Indische Regeering, met volkomen instemming van het Opperbestuur, volharden bij hetgeen zij meende te mogen noemen hare "masterly inactivity", bij het systeem van doorzieken, totdat de zaken door het met de prijsdaling van het zilver ten nauwste verband houdend dalen van den wisselkoers zoo schromelijk in de war liepen, dat de toestand voor land en volk eenvoudig onhoudbaar werd, en zoo kwam men er na veelvuldige en langdurige beraadslagingen ten slotte toe om met ingang van 26 Juli 1893 te doen wat ons land bereids een kleine twintig jaren vroeger gedaan had, de munten te Bombay en Calcutta te sluiten voor de verdere aanmunting van zilver door particulieren. Maar door dezen op zich zelf onvermijdelijken maatregel kwam de zaak nog geenszins in het reine. Integendeel de verwarring werd er te grooter door, want Indie had nu in het geheel geen muntstandaard meer, evenals dit ten onzent een korten tijd het geval is geweest voor dat tot de definitieve invoering van den gouden standaard bij de wet van 5 Juni 1875 werd besloten. Nieuwe moeilijkheden en verwikkelingen waren er het gevolg van en deden de Regeering te staan komen voor een toestand, die aan het bij ons uit de geschiedenis van het noodlottige jaar 1672 bekende ,redeloos, radeloos en reddeloos" herinnert - een toestand, die, zooals niet ten onrechte werd opgemerkt "had made confusion worse confounded". ')

1) Voor meer bijzonderheden omtrent den toenmaligen uiterst bedenkelijken munttoestand in Britsch-Indië zij verwezen naar mijn in de Gids van Maart en April 1894 opgenomen opstel over het muntvraagstuk aldaar. Sedert werd de questie hier te lande, voorzoover mij bekend, alleen besproken door den Heer G. M. Boissevain, in de Economist van 1899 , bl. 536 v.v. en 1903, bl. 1023, v.v.; maar in Duitschland bleef zij zeer de aandacht trekken. Achtereenvolgens verschenen daar de volgende mij bekende monografien;

K. Ellstaetter; Indiens Silberwährung; Stuttgart, 1894. 
Gelijk onder omstandigheden van dergelijken aard veelal te doen gebruikelijk is, werd de zaak van het muntwezen opnieuw commissoriaal gemaakt. De te dien einde door het Opperbestuur ingestelde commissie begon in Mei 1898 onder voorzitterschap van Sir Henry.H. Fowler, den lateren Lord Wolverhampton, hare werkzaamheden, die bepaaldelijk ten doel hadden om te overwegen welke maatregelen te nemen waren "to make effective the policy adopted in June "1893 by the closing of the Indian mints to what is known "as the free coinage of silver", en de ter zake in haar onder dagteekening van 7 Juli 1899 aan de Regeering ingediend eindverslag vervatte voorstellen, waaraan bij de Indische verordening Act XXII van 10 September d. a. v. kracht van wet verleend was, zijn sedert tot den huidigen dag de grondslag gebleven, waarop het tegenwoordige samenstel der Britsch-Indische muntregeling rust. In hoofdzaak komt zij hierop neder, dat de goudwaarde van de ropij werd yastgelegd in verhouding van 1 ropij voor 16 pence $(1$ sh. 4 ), terwijl tegelijkertijd de sovereign met de halve sovereign als wettig betaalmiddel erkend werd als equivalent voor 15 ropijen, met dien verstande, dat de Regeering zich verbond tot aanneming van goud tegen ropies op den vastgestelden voet, maar het omgekeerde, namelijk de verplichting van de Regeering tot levering van goud tegen ter verwisseling aan te bieden ropijen, bleef achterwege. Dit nu bleek spoedig het zwakke punt van de nieuwe muntregeling uit te maken, zooals trouwens van den aanvang af moest erkend worden. Ter volmaking der hervorming in dit opzicht, was in de Commissie wel het denkbeeld besproken om ter verzekering van de goudwaarde van de ropy te besluiten tot het doen ontmunten van een nominaal bedrag van 200 millioen

Dr. O. Heyn; Der Indische Silberzoll und die Hebung des Rupiencourses; Berlin 1894.

Dr. O. Heyn; Die Indische Währungsreform; Berlin, 1903 (375 bl.).

Dr. A. Arnold; Das Indische Geldwesen unter besonderer Berücksichtigung seiner Reformen seit 1893; Jena, 1906 (344 bl.).

Dr. K. Singer; Die Motive der Indischen Geldreform; Strassburg, 1910; terwijl Prof. W. Lexis in verschillende bladen menige grondige studie aan het onderwerp gewijd heeft. 
ropijen, en ter dekking van het hierop te lijden verlies eene leening te sluiten van 20 millioen, waarvan de opbrengst in goud zou worden ter zijde gelegd als reserve ter handhaving van den aangenomen ropijkoers, terwijl tevens de openstelling werd aanbevolen van de muntinrichtingen te Bombay en Calcutta voor het aanmunten van sovereigns op gelijken voet als in het moederland zelf; maar noch het een noch het ander durfde men aan. Het eerste niet om de financiele consequenties, en ook omdat ontmunting onnoodig geacht werd met het oog op den middelerwijl tamelijk standvastig gebleven wisselkoers; het tweede niet, omdat "the actual operations of the coinage "of sovereigns, the standard gold coin, are conducted in "England and Australia without expence to India". ${ }^{1}$ )

Werkelijk bleek weldra, in plaats van ontmunting, de aanmunting van nieuwe ropijen een dringende eisch van het verkeer te worden, en zeer wijselijk werd nu besloten om de met dergelijke aanmunting te kweeken winst niet te bezigen als eene gewone inkomst van den Staat; doch als een in goud te beleggen muntfonds om daarvan naar omstandigheden gebruik te maken, - een muntfonds, dat geheel afgescheiden zou worden gehouden van de grootendeels in Engeland in goud en staatsfondsen aanwezige reserve voor het in Britsch-Indië van staatswege uitgegeven fiduciair papier, de aldaar omloopende Currency notes. ${ }^{2}$ )

1) H. F. Howard, India and the gold standard; Calcutla, 1911, p. 10.

2) Sedert de muntregeling van 1899 tot en met het dienstjaar 1911/1912, is aan groot en klein zilvergeld voor een nominaal bedrag van niet minder dan 1.381 .406 .000 ropijen aangemunt, waarmede tot en met het dienstjaar 1910/1911 (latere gegevens heb ik niet ter mijner beschikking) een winst is geboekt van $£ 16.965 .000$ (Statement exhibiting the moral and material progress and condition of India during the year $1910-1911$; p. 20), waaruit met inbegrip van geaccumuleerde rente een muntreservefonds is opgebouwd van $£ 19.260 .129$, dat als volgt was samengesteld:

Sterling securities (at cost price) . . . . . . . 115.848 .469

Silver (coined rupees in India). . . . . . . . , 1.934 .302

Cash in England (placed at short notice). . . . " 1.477.358 Aanvankelijk werd de gemaakte winst geheel ten bate van het 
Reeds spoedig intusschen zou de ervaring leeren, dat hiermede de muntaangelegenheden van het land nog geenszins in het rechte spoor gebracht waren. Aanvankelijk bleef alles naar wensch gaan. Naamwaardige schommelingen in den vastgestelden pari-koers van 1 sh. 4 kwamen jaren achtereen niet voor, tot het najaar van 1907, toen door het gedeeltelijk mislukken van den Indischen graanoogst aan den eenen kant, en den gespannen toestand der Londensche geldmarkt wegens de het geheele wereldverkeer uit zijn verband gerukt hebbende geldcrisis in de Vereenigde Staten van Noord-Amerika aan den anderen kant, de voor Indië in den regel gunstige handelsbalans zich in tegenovergestelden zin begon te wijzigen en de behoefte aan remise dientengevolge eensklaps onverwachte verhoudingen aannam. De zilveren landsmunt, de ropij, kon hierbij geen dienst doen, daar zij nergens ter wereld voor meer dan de te hoog geschatte metaalwaarde bruikbaar zijn kon, - en goud was niet verkrijgbaar, daar de Regeering huiverig was om het onder haar beheer staand muntfonds aan te spreken, en aanvankelijk althans ongezind bleek om het verkeer met een deel er van te gerieven. In de gegeven omstandigheden, bij het ontbreken van eene centrale circulatiebank, die hulp had kunnen verstrekken, werd rijzing van den wisselkoers boven pari, dus depreciatie van het ruilmiddel, onvermijdelijk, en inderdaad bleef die rijzing niet uit; maar aangezien tot grondslag van de wisselnoteering tusschen Calcutta en Londen voor Calcutta het "certain" en voor Londen het "incertain" is aangenomen, wordt eene stijging in den wisselkcers in de noteering met dalende cijfers weergegeven. Van den parikoers van 1 sh. 4 nog slechts een paar dagen te voren, zakte de noteering voor zicht Londen op den $23^{\text {sten }}$ November tot 1 sh. $3 \frac{3}{4}$ of circa 2 percent boven goudpariteit, en volgens de Times of India van dienzelfden dag was het niet twijfelachtig, "that unless gold is

muntreservefonds aangehouden, totdat gedurende twee jaren, 1909/1910 en 1910/1911 de helft er van gebezigd werd voor spoorweguitgaven, een maatregel, waarop sedert weder is teruggeliomen. Het voor spoorweguitgaven gebezigde deel van de winst heeft bedragen $£ 1.123 .604$. 
"released by Government the rate may fall as low as 1 "sh. 2" hetgeen eene stijging van den koers tot $12 \frac{1}{2}$ percent boven goudpariteit zou beteekend hebben. Maar door ter elfder uur tot andere inzichten te komen heeft de Regeering het dreigende gevaar weten te bezweren. Zij stelde binnen zekere grenzen goud beschikbaar in den vorm van aanwijzingen op hare in Londen aanwezige goudreserve, en het genoemde blad kon de zaak verder laten rusten onder opmerking in zijn nummer van 30 November, "that "if Government had allowed gold to go forth from the "commencement without demur, no such dislocation as has "afflicted the market would have occurred".

Het was, gelijk het financieele iid van den Wetgevenden Raad van India, Sir Guy Fleetwood Wilson, het bij de indiening der begrooting voor het dienstjaar 1910/11 te verstaan gaf, de eerste maal sedert de munthervorming van 1899 dat de Regeering "a strenuous campaign" heeft te voeren gehad, "against the fall in exchange - the first "that had been forced upon them since the adoption of the "gold standard"; doch tevens gaf hij de meest ondubbelzinnige verzekering, dat voor eene herhaling van het toen door het verkeer geleden ongerief niet de minste vrees behoefde gekoesterd te worden. "To hoard our gold when there is "a clear case for employing it", dus sprak hij bij diezelfde gelegenheid, „would be fatal to our currency policy, and "it may, and usually will be just as much our duty to "disperse our reserve when the balance of trade is against "India, as it is our duty to build them up when the balance "is in our favour. The increasing delicacy of the exchange "standard may require us to open our gold reserves more "often than has hitherto been necessary; but we shall not "hesitate to do so whenever exchange clearly needs support"; terwijl hij zijne rede besloot met het uitspreken van het vertrouwen, dat allen wier belangen het aangaat niet langer meer twijfelen zullen aan "the determination of those who "are responsible for the Government of India to uphold "the gold value of the rupee."

De slotsom van het voorafgaande kan, dunkt mij, geen ander wezen dan dat Engeland en Nederland met betrekking 
tot de muntaangelegenheden hunner koloniën in den grond der zaak op volkomen hetzelfde standpunt staan, en dat in dit opzicht Nederlandsch-Indië niets te benijden heeft aan Britsch-Indië, daargelaten natuurlijk de omstandigheid, dat ter handhaving van de goudwaarde van de ropij thans reeds eene zeer aanzienlijke goudreserve zich in handen der Engelsche regeering bevindt, en dat ons zilvergeld tegenover het goud veel hooger gewaardeerd is dan sedert 1899 de toen verre beneden de vroegere pariteit gedeprecieerde ropij, zoodat ons land dus bij eventueele ontmunting van zilver voor een in verhouding veel aanzienlijker verlies dan Engeland zal te staan komen. ') Al moge het nu niet met even zooveel woorden in de wederzijdsche wetgevingen hunner regeeringen geschreven staan, dat zij respectievelijk verantwoordelijk zijn voor de goudwaarde van de in Britsch-Indië omloopende ropijen en de guldens in Nederlandsch-Indië, aan die verantwoordelijkheid valt niet te ontkomen, en zoo komt het ten slotte vrij wel op hetzelfde neder dat bij eventueele oververzadiging van den omloop met zilvergeld de overtollige ropijen in de muntinrichtingen te Bombay en Calcutta zullen moeten worden versmolten, en onze guldens in geval van eene economische inzinking van Indië naar het moederland zullen teruguloeien en de dan misschien onvermijdelijke ontmunting er van geschieden zal door versmelting in de munt te Utrecht. Al hadden zij van den beginne af een ander uiterlijk gehad dan de sedert 1847 naar onze bezittingen uitgevoerde muntstukken, de toestand, wat de aansprakelijkheid van den Staat betreft, zou volkomen dezelfde zijn als de tegenwoordige.

Zal nu het door den heer Cremer ter zitting der Eerste Kamer van 29 October jl. aanbevolen denkbeeld tot ommunting der thans in Indië als wettig betaalmiddel dienstdoende zilveren teekenmunt in een van een Indisch stempel

1) Volgens onze muntregeling is de betaalkracht van 945 gram fijn zilver gelijkgesteld met 0.6048 gram fijn goud, eene verhouding dus van pl.m. $15 \frac{1}{2}$ tot 1 . In Britsch-Indië hebben 15 ropijen van 165 grein fijn zilver, of 2475 grein fijn zilver gelijke betaallracht als 1 sovereign met 233 grein fijn goud, eene verhouding dus van pl.m. 22 tot 1 . 
voorziene nieuwe munt, den Staat der Nederlanden voor de mogelijke gevolgen van die aansprakelijkheid kunnen vrijwaren? Zijns inziens zou eene dergelijke operatie met gesloten beurzen kunnen geschieden. „Op de tegenwoordige "zilverprijzen immers" zegt hij „wordt ongeveer 50 percent "bij aanmunting verdiend. Indien dus de regeering met ge„bruikmaking van de bij art. 3 der Indische muntwet van „31 October 1912 verkregen machtiging een begin mocht "maken met de aanmunting van 10 millioen nieuwe zilveren "teekenmunt, zal daarop een winst van 5 millioen behaald „worden. Gaat men nu die 5 millioen gebruiken om de nu „in Indië aanwezige zilveren munt allengs naar Nederland "te zenden en ze na ommunting te Utrecht tot de aanbe"volen nieuwe munt naar Indië terug te zenden, dan zal "eene dergelijke operatie niet meer kosten dan ongeveer "twee ten honderd. Voor de 5 millioen winst, die men "heeft behaald met de aanmunting van de 10 millioen zou "men dus voor 250 millioen grof zilver van Indië naar "Nederland kunnen laten komen om ze aldus te behandelen".

Het denkbeeld van den heer Cremer, zooals het hier met zijne eigen woorden is weergegeven, heeft zeker iets aantrekkelijks in zoover het bezitten van geldstukken met eigen muntslag zou kunnen gelden als symbool van die meerdere zelfstandigheid van Indië, waarvoor ik van oudsher meermalen heb geijverd. Maar is het uitvoerbaar? I betwijfel het. Zal het ter inwisseling oproepen van de wettige betaalmiddelen, waaraan het verkeer nu reeds langer dan een halve eeuw gewend is, tegen de met Indischen stempel nieuw aan te munten rijksdaalders, guldens en halve guldens, onder eene op muntgebied zoo bijzonder achterdochtige bevolking als zij meermalen heeft getoond te zijn ${ }^{1}$ ), niet

1) $" \mathrm{De}$ tot een bedrag van $\mathrm{f} 8.100 .000$ ingevoerde rijksdaalders waren voor het meerendeel nog nimmer in circulatie geweest en verpakt in zaklen van het zegel van 's Rijks munt voorzien, en toch bleek bij de uitgifte, dat zij hier en daar gewantrouwd werden omdat splinternieuwe munt bevreemding wekte.»

Verslag van de President der Javasche Bank (J. Reysenbach) over het boekjaar $1899 / 1900$; bl. 20.

"Zoowel van Regeeringswege als door ons werd de aandacht van het publiek gevestigd op het feit, dat de nieuwe muntslag der geïmporteerde pasmunt en kleine standpenningen eenigszins van 
allerwege groote ontroering te weeg brengen en een misschien bedenkelijken schok geven aan het thans bestaande vertrouwen in den toestand van ons Indisch muntwezen, een vertrouwen dat voor de verdere economische ontwikkeling van Indië volstrekt onmisbaar is?

Maar aangenomen voor een oogenblik, dat de geopperde bezwaren geheel denkbeeldig zijn, dat de maatregel op den aangegeven voet zijn beslag krijgt, waar zal de voorgestelde hervorming dan ten slotte toe leiden? Tot het verkrijgen door Indië van eene nieuwe eigen munt, die in het moederland niet gangbaar zijn zal, evenmin als onze Indische kwartjes en dubbeltjes, wat onder de bestaande toestanden, nu de Javasche Bank haar goudvoorraad tot meer dan het dubbele van den zilvervoorraad heeft weten op te bouwen, op zich zelf een vrij onverschillige zaak zou kunnen geacht worden; maar die niettemin standaardmunt, dus wettig betaalmiddel voor het verkeer in Indië blijven moet, en voor de handhaving van de goudwaarde waarvan de Nederlandsche Staat evenzeer aansprakelijk moet blijven als Engeland ten slotte voor de goudwaarde van de ropy, want het zal toch wel niemand in den zin komen kunnen om aan de van een Indischen stempel te kenmerken nieuw aan te maken rijksdaalders, guldens en halve guldens het karakter van' standaardmunt te ontnemen, en ze als pasmunt alleen tot een beperkt bedrag als betaalmiddel toe te laten. Het zou een toestand van verwarring op muntgebied in het leven roepen grooter dan Indië in de erbarmelijke jaren voor 1846 , toen de invoering van het recepissenstelsel tijdelijk in afwachting van nader te treffen regelingen een eind kwam maken aan den voor het maatschappelijk en handelsverkeer inderdaad onhoudbaar geworden toestand, ooit beleefd heeft. In dit opzicht zal dus alles eigenlijk bij het oude blijven bij verwezenlijking van het door den Heer Cremer aanbevolen denkbeeld, en al moge nu, te dien

den ouden afwijkt, en zulks ter voorkoming dat die afwijkingen verdere aanleiding tot wantrouwen zouden geven, hetgeen zich reeds hier en daar openbaarde, nu men eenmaal hier zooveel meer dan in het moederland de munt aan kritiek onderwerpt.»

Verslag van de President der Javasche Bank (J. Reisenbach) over het boekjaar $1904 / 1905$; bl. 23. 
einde, aan de Javasche Bank de verplichting worden opgelegd tot handhaving der goudwaarde van het Indische ruilmiddel op den voet van de bij de jongste vernieuwing van haar octrooi door de Nederlandsche Bank afgegeven verklaring, dat zij bij stijging der wisselkoersen op het buitenland boven de pariteit der goudwaarde haren goudvoorraad, zoolang zij daartoe bij machte zijn zal, voor uitvoer beschikbaar zal stellen op den voet van $f 1653.44$ per kilogram voor baren fijn en tot hiermede overeenkomende prijzen voor gouden muntspecien, - voor de in die verklaring niet onmogelijk geachte machteloosheid der Nederlandsche Bank zal de Javasche Bank oneindig meer kans loopen, want tot welke hoogte haar goudvoorraad ook zal aanzwellen, tegenover den reusachtigen omvang van den door het verkeer in Indië opgenomen zilvervoorraad, ${ }^{1}$ ) waarvan onder ongunstige omstandigheden zeker een goed deel naar de kassen der Javasche Bank zal terugvloeien, kan handhaving der goudpariteit hare krachten

1) Naar de hoeveelheid van het in Indië in handen der bevolking zich bevindende zilvergeld kan slechts op ruwe wijze gegist worden. In 1883 werd hieromtrent van Regeeringswege de meening gevraagd van de Directie der Javasche Bank, hetgeen haar aanleiding gaf tot het instellen van een nauwgezet onderzoek, waarvan zij de uitkomst ter kennis bracht van den Directeur van Financiën bij uitvoerig schrijven van 23 Juli 1883, dat als bijlaag is toegevoegd aan het jaarverslag over boekjaar 1883/1884, en eindigde met de slotsom, "dat tegenover den met vrij veel juistheid bekenden invoer van Nederlandsch zilvergeld binnen Nederlandsch.Indië, omtrent den wederuitvoer en het zich daarmede parende verdwijnen van zilveren munt niets zekers te zeggen valt, en dat mitsdien de gestelde vraag, hoeveel zilvergeld alsnog gerekend kan worden in Nederlandsch-Indië in omloop te zijn niet voor eene ernstige beantwoording vatbaar is.»

In datzelfde schrijven wordt ook melding gemaakt van een ter zake in Britsch-Indië ingesteld onderzoek, volgens de resultaten waarvan de in handen der bevolking zich bevindende muntvoorraad in 1876 zou bedragen hebben 1400 millioen ropijen of pl. m. 7 ropij per hoofd der bevolking; doch volgens meer recente onderzoekingen (Economic Journal 1891 en 1892) zou een bedrag per hoofd aan grof en klein zilver van ongeveer $4 !$ ropij meer aanneembaar zijn. Of uit deze onderzoekingen, omtrent den zilvervoorraad van N.-I., gevolgtrekkingen te maken zijn, wensch ik aan anderer oordeel over te laten. 
licht te boven gaan. Men vergete bovendien niet, dat de waarborg voor de deugdelijkheid van het Nederlandsche muntwezen niet gelegen is in de zooeven in herinnering gebrachte verklaring der Nederlandsche Bank, - bij het opstellen waarvan ik indertijd soms wel eens meesmuilend denken moest aan het bekende briefje van la Chatre, maar in de bepaling van onze muntwet, dat als de nood aan den man komt de Regeering verplicht is om over te gaan tot ontmunting voor hare rekening van het eventueel overtollig geworden zilver voor een bedrag van f 25 millioen, welke verplichting ik intusschen met den Heer Van Nierop (zitting Eerste Kamer van 29 October jl.) gaarne vervangen zou zien door eene naar gelang van omstandigheden te regelen bevoegdheid tot ontmunting.

Inmiddels zijn wij door den nog kort geleden geheel onvoorzienen loop van zaken voor een volkomen tegenovergesteld geval te staan gekomen. Terwijl de zilvervoorraad der Nederlandsche Bank gedaald is verre beneden het peil, dat ten behoeve van hare operatiekracht, zooals die zich afspiegelt in haar ,beschikbaar metaalsaldo", in vele gevallen wenschelijk zijn kan, is voor de eischen van het verkeer in Indië aanmunting van zilvergeld uit te dien einde door de Regeering in te koopen baren niet langer te ontgaan, en wel op den voet van de herziene muntwetten van 31 October jl. Stbl. No 324-5, krachtens welke reeds dadelijk moet begonnen worden met het aanleggen van een muntreservefonds, dat ter bekwamer tijd bij het omslaan der balans en daarmede eventueel gepaard gaande noodzakelijkheid tot ontmunting van zilver goede diensten zal kunnen bewijzen.

Dank zij die wetten is de teedere aangelegenheid van ons muntwezen, zoowel het Nederlandsche als het NeerlandschIndische, thans m.i. naar eisch geregeld, en de eenige wijziging, die in mijn oog nog aanbeveling kan verdienen ware opneming in de wet van de verklaring, dat het goud de grondslag is van beider muntregelingen, en de bepaling dat bij eventueele ontmunting van zilver de Regeering niet zal gebonden zijn aan het in de wet vastgelegde bedrag van 25 millioen gulden, want die limiet heeft, volkomen terecht werd het door den heer Van Nierop opgemerkt, hoegenaamd geen 
zin. Intusschen zal daarmede feitelijk niet de minste verandering gebracht worden in den thans bestaanden toestand, en het is voornamelijk op grond hiervan, dat het denkbeeld van de heeren Cremer en Van Nierop tot instelling van een Staatscommissie ter onderzoeking van onze muntaangelegenheden mij voor het oogenblik althans allerminst noodzakelijk voorkomt, evenmin als men er aan gedacht heeft bij de in 1901 door Minister Pierson tot stand gebrachte codificatie van het muntwezen. $\mathrm{lk}$ acht het denkbeeld inopportuun, want voor het ter bekwamer tijd aanbrengen van de aangegeven wijzigingen is het advies van eene Commissie ad hoc niet noodig, terwijl het instellen van Staatswege van een onderzoek als het beoogde licht wantrouwen wekken kan omtrent de deugdelijkheid der grondslagen van ons muntstelsel, ten nadeel misschien van het crediet, dat Nederland thans allerwege geniet, en waaraan Indië in de tegenwoordige phase van zijne economische ontwikkeling meer dan ooit vroeger behoefte heeft.

Waar het $\mathrm{m}$. i. voor het oogenblik alleen op aankomt is, dat van Regeeringswege niets verzuimd worde om te voorzien in de behoefte aan zilveren ruilmiddelen, standaardmunt en pasmunt, die het verkeer in Indië niet kan ontberen. $\mathrm{Zij}$ alleen toch is bij machte aan die zoo sterk sprekende behoefte tegemoet te komen. Voor het overige zou naar mijn oordeel het "quieta non movere" voorshands de lęus behooren te blijuen.

N. P. van den Berg. 